\title{
CEQUES Y DAMEROS: LA REDUCCIÓN INDÍGENA DE SANTIAGO DEL CERCADO. REINHARD AUGUSTIN BURNEO. LIMA, UNIVERSIDAD RICARDO PALMA, VICERRECTORADO DE INVESTIGACIÓN, 2016.
}

\author{
Omar YALLE QUINCHO \\ Universidad Ricardo Palma \\ omar.yalle@urp.edu.pe
}

a Universidad Ricardo Palma a través del auspicio de su Vicerrectorado de Investigación, nos ofrece el trabajo de Reihard Augustin Burneo, titulado: Ceques y Dameros: La Reducción Indígena de Santiago del Cercado. El autor, es un arquitecto graduado en esta casa de estudios, y que desarrolla como línea de investigación la historia de la arquitectura colonial limeña. En ese sentido, su vocación por la investigación, lo vincula con otras disciplinas de las Ciencias Sociales, en particular, con la historia y la antropologia. Entre sus trabajos más resaltantes podemos destacar; "Origen y evolución del conjunto arquitectónico de la Casona

Reinhand Augustin Burnee

CEQUES Y DAMEROS:

La reducción indigena de Santiago del Cercado

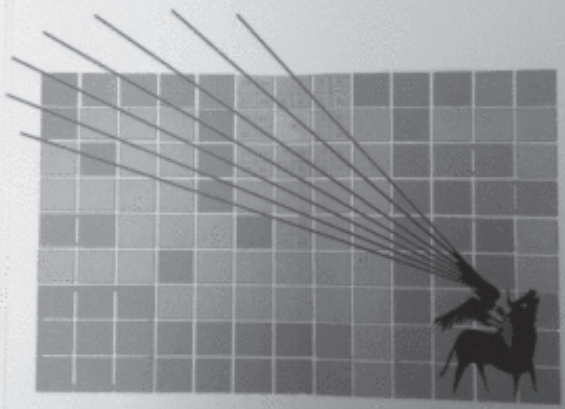

(5)

Vicentrictoralo de 1 he de San Marcos"y "Las Murallas Coloniales de Lima Callao Arquitectura Defensa y su Influencia en la Evolución de la Capital"

Ceques y dameros: la reducción indígena de Santiago del Cercado, está dividido en dos partes; el capítulo primero: El damero: del rito a la norma, tiene siete apartados. Allí se describe el Damero como una institución europea de organización del espacio social y geográfico urbano. La forma de ocupar un territorio, de establecer centros poblados y fundar nuevas ciudades, permiten comprender su formación física, crean el escenario que se materializa a partir de esta simbiosis. Así, el espacio territorial no solo constituye un espacio físico en si, sino que a partir de ello, se dan pautas de comportamiento y valores ritualizados desde lo religioso, pero también desde las leyes y ordenanzas que la legitima.

El Damero, como forma de organizar el espacio físico y social constituye, "...todo un proceso, vinculado históricamente por medio de diversos y complejos ritos y ceremonias 
que buscan, establecer un centro simbólico del universo, a partir del cual se trazarían los ejes de la nueva cuidad, asegurando su correcto anclaje con el orden y las fuerza naturales y divinas" (p. 11). Así los mitos y ritos fundacionales antiguos de occidente y del mundo antiguo podían variar, sin embargo ninguna ciudad antigua podía ser fundada sin el oficio de ceremonias mágico/religiosas, que justifique su aparición ( p. 24). La instrucción divina no solo revela el lugar, con las condiciones geográficas y naturales sino que además dirige a los fundadores, hacia un territorio que contará con la aprobación y el auspicio de las divinidades, un factor fundamental para el próspero devenir y la buena ventura de la ciudad y sus habitantes (p. 24).

En el presente trabajo, el autor también hace análisis de tipo comparativo respecto a los ceques y los dameros. El primero es concebido como una forma de integración de los trazos y caminos en épocas preincaicas. Estas líneas, pudieron ser reales e imaginarias, que permitieron conectar los centros poblados dentro de un espacio físico, el templo, y el apu, u adoratorio principal de la religión, señalando así el camino que debían seguir los pasos, 0 los pensamientos y peticiones hacia la casa de sus ídolos, articulando un flujo permanente de radiación y retroalimentación simbólica que daba cohesión e integraba el cosmos con el territorio (p. 118)

Por el contrario, el Damero como una institución arquitectónica fundada a partir de tiros y trazos iniciales en las ciudades arcaicas europeas, ha ido en constante trasposición y modificación de sus estructuras alrededor del espacio central de las ciudades, haciendo imposible identificar sus trazos y construcciones iniciales que establecieron sus fundadores (p. 13) tanto en Grecia como en Roma, y luego en otras partes de Europa como en España. El Damero fue una imposición como patrón urbano de las nuevas fundaciones, llevadas a cabo por los conquistadores de América y la fundación de nuevas ciudades en territorio americano desde fines del siglo XV $\mathrm{d}$. C.

La trama ajedrezada del Damero de Lima, para la reducción indígena de Santiago del Cercado, así como para la mayoría de las nuevas poblaciones españolas y de reducción de indígenas en América, fue instituyéndose paulatinamente durante la primera parte del siglo XVI, mediante la implementación y práctica casi espontanea primero, bajo leyes y decretos reales luego, que además de detallar el modo ético de actuar, de viajar, y la manera de establecer relaciones sociales con los oriundos de los nuevos territorios, daban instrucciones sobre la nuevas formas de explotar las riquezas naturales, de tomar posesión de las tierras y las maneras apropiadas de trazar y urbanizar sus nuevos poblados" (p. 15).

Por otro lado el papel de los oráculos y las entrañas, dio sustento mítico a la mayor parte de ceremonias de apropiación del territorito a partir de interpretaciones de la naturaleza y sus elementos, de los seres vivos, como los animales, en distintas épocas prehistóricas de Europa y América prehispánica. En el caso de la cosmovisión y la mitología andina, los oráculos fueron determinantes en las más remotas culturas prehispánicas para la fundación de ciudades, la búsqueda de respuestas a decisiones controversiales, la indagación sobre el resultado de las batallas, la búsqueda de recetas para la salud de los seres humanos, y el conocimiento de disputas en general (p. 26). Allí tenemos el oráculo del Lago Titicaca y Pachacamac. Este último, se constituyó en el centro de adoración más importante de la costa del pacífico después de la caída del imperio Wari. 
A diferencia de la tradición prerromana de fundar ciudades o campamentos guiados por el oráculo, los augures y, el sacrificio de animales, en la fundación de ciudades en la América española, no fueron las supersticiones ni las creencias, lo que guiaron a Francisco Pizarro y a sus acompañantes, sino la visión netamente militar y táctica que respondiera a los afanes de descubrimiento y expansión de la corona española. Así la fundación de Lima fue más bien preestablecida, y guardaba naturalmente las condiciones geográficas y político-militares del momento para el buen devenir de la conquista, en ese sentido:

"Las fundaciones de ciudades españolas en la edad media constituían un acto jurídico y aunque contendría elementos vinculados a lo religioso, no estaría ya regida por los principios míticos de ninguna cultura, encontrándose cada vez más inmersa en el derecho, las cartas y los escritos de jurisdicción, olvidados o desfasados por el tiempo, el mito y el rito se transforman en ley y letra" (p. 51).

Pero los fundadores de ciudades adquieren también un albur mítico, una revelación para establecer sus asentamientos. Lo fue Wiracohca como el héroe y creador de la civilización andina, lo fue Pachacutec Yupanqui, el gran hacedor del imperio incaico, así como el Marques Francisco Pizarro, el conquistador proveniente de España. Así el héroe fundador, es entrelazado entre la historia y la leyenda que le da un carácter mitológico de ser sobrenatural de representación. Pero esto también tiene su fin, sus epílogos reynales, de disputas y traiciones que inician otras historias.

Una vez elegido el territorio donde se fundaría la ciudad, se procedería a tomar posesión del terreno al Inaguratio; este era también un proceso complejo y tenía tres etapas principales; el Cortejo, el Conspicio y el Cortumio. Luego empezaría la lectura de los buenos auspicios y augurios para la ciudad y sus habitantes

El trazado y la fundación constituía todo un rito ceremonial tanto en las antiguas culturas de occidentes, en especial la latina, como aquellas dadas y establecidas en el mundo andino. El agrimensor latino para el caso europeo, cumplía la labor de orientador y lotizador, que empezaba con el sorteo y reparto de los terrenos. Las diferencias sociales eran marcadas en los territorios, entre la población común y las autoridades y familias importantes. Para el mundo europeo, cada ciudad era un mundo, pues así era creado, con un alto nivel de independencia y un sentido de localidad. En el caso de las ciudades fundada por los españoles, se superponen, la existencia de poblados previos con pobladores nuevos. Sin embargo, la fundación de la ciudad de los reyes sobre el pueblo y asiento de Lima, parece quedar comprobada, según las referencias de quienes lo conocieron y escogieron, como el mejor lugar para perpetuar en él la Capital (p.45).

La segunda parte del trabajo, comprende seis subcapítulos, y nos ubica en el Urbanismo y resistencia: la reducción indígena de Santiago de Cercado. Una de las instituciones que trajo España al continente americano fue sin duda las reducciones o pueblo de indios. Esta nueva forma de organización social, económica y política, permitió a la corona en sus inicios, una mejor administración del orden colonial. El virrey Francisco de Toledo, tuvo un papel protagónico en ese sentido a partir de 1569.

La reducción española en América tuvo como finalidad, la concentración de la población nativa en centros urbanos para la recaudación de tributos, los repartimientos 
de los corregidores y la disposición de la fuerza de trabajo indígena, así mismo, facilitar el adoctrinamiento y evangelización de los naturales.

Mucho antes que Barrios Altos, en el actual Cercado de Lima, fuese un lugar populoso y de tradición del criollismo, fue una reducción indígena española, como parte del proceso de población extirpación de idolatrías y evangelización durante el siglo XVI. Santiago Apóstol del Cercado constituía una edificación de adobe, siendo su entrada principal donde actualmente se ubica Cinco Esquinas. Su organización arquitectónica, obedeció a cánones españoles del damero, sin embargo, es claro identificar que fue superpuesto en líneas y trazos que identifican el diseño de los antiguos pobladores prehispánicos, a partir de un sistema de organización conceptual y espacial de sus calles hacia el valle y las huacas.

Debido al carácter militar y evangelizador de las fundaciones españolas en América, estas adoptaron el modelo de damero o campamento romano, lo que favorecía la defensa y una clara jerarquización de clases sociales. Por otro lado, las reducciones permitieron maximizar la fuerza de trabajo indígena y hacer eficiente el cobro de tributos, facilitar su evangelización y el control de posibles rebeliones.

Entre las primeras reducciones indígenas de Lima, distinguimos; la de Santa María Magdalena de la Chacalea, hoy Magdalena Vieja, creada en 1557 por el virrey Hurtado de Mendoza. Sin embargo, como señala el autor, esta no fue la única. García de Castro, encargado del virreinato entre 1564 y 1569, decidió crear una reducción al este de la ciudad, en tierras del licenciado don Rodrigo Niño. Su fundación oficial como la reducción de Santiago Apóstol del Cercado se dio el mismo día que la consagración de su iglesia, el miércoles 25 de julio de 1571. (p. 97)

A diferencia de otras reducciones, la autoridad en Santiago del Cercado no recayó en un cacique local, sino en un corregidor. Cabe destacar: la casa e iglesia de Santiago Apóstol; el colegio El Príncipe, para los hijos de los caciques; y la cárcel de hechiceros o Casa de la Santa Cruz, para dogmatizadores, brujos y ministros de idolatrías. Para mediados del siglo XVII, la reducción tenía alrededor de 200 casas y unos 800 ocupantes. El poblado original fue mutilado hacia 1687 con la construcción de las murallas que rodearon Lima: una parte quedó integrada a la ciudad, y desapareció el sector de extramuros.

En las reducciones indígenas, la utilización del esquema de Damero tuvo la función de transformar la idiosincrasia del hombre indígena propiciando un mestizaje cultural a partir de costumbres y creencias, lo que posibilitó el ordenamiento urbano que facilitaba la aculturación.

La importancia del texto, radica entre otras cosas en identificar, algunos nuevos elementos a partir de su trazado, la evolución urbana del Cercado de Lima; por otra parte, cómo las reducciones indígenas, constituyen una temprana y discreta forma de hibridación entre los urbanismos de ambos mundos. 